\title{
BMJ Open Cross-sectional study of parental knowledge, behaviour and anxiety in management of paediatric fever among German parents
}

\author{
Sara Hamideh Kerdar (D , ${ }^{1}$ Christina Himbert, ${ }^{1}$ David D Martin, ${ }^{1,2}$ \\ Ekkehart Jenetzky (D) 1,3
}

To cite: Hamideh Kerdar S, Himbert C, Martin DD, et al. Cross-sectional study of parental knowledge, behaviour and anxiety in management of paediatric fever among German parents. BMJ Open 2021;11:e054742. doi:10.1136/ bmjopen-2021-054742

- Prepublication history for this paper is available online. To view these files, please visit the journal online (http://dx.doi. org/10.1136/bmjopen-2021 054742).

Received 21 June 2021 Accepted 05 October 2021

Check for updates

(C) Author(s) (or their employer(s)) 2021. Re-use permitted under CC BY-NC. No commercial re-use. See rights and permissions. Published by BMJ.

${ }^{1}$ Faculty of Health/School of Medicine, Witten/Herdecke University, Witten, Germany ${ }^{2}$ Clinic for Paediatrics and

Adolescent Medicine, University of Tübingen, Tübingen, Germany ${ }^{3}$ Department for Child and Adolescent Psychiatry and Psychotherapy, University Medical Center, Johannes Gutenberg University Mainz, Mainz, Germany

Correspondence to

Professor Ekkehart Jenetzky;

Ekkehart.Jenetzky@uni-wh.de

\section{ABSTRACT}

Objectives Fever is a common symptom among children. Parental lack of knowledge about fever could cause anxiety and lead to unnecessary measures to subside fever. There is little evidence about German parents' knowledge and their fever management.

Design A cross-sectional study using a paper-based questionnaire.

Setting 16 kindergartens in Saarbrücken and Saarlouis regional association accepted to participate in the study. Parents from these kindergartens were requested during the pickup time to answer the questionnaire.

Participants 481 German parents participated in the study, 394 of them were women. Inclusion criteria were good understanding of German and being a parent of at least one child below the age of 7 years.

Primary and secondary outcome measures Knowledge and behaviour of parents on paediatric fever management and the factors influencing fever anxiety.

Results The older the parents were, the more anxiety they reported. Their definition of fever had a wide range of $30^{\circ} \mathrm{C}-41^{\circ} \mathrm{C}$ (mean $38.46, \mathrm{SD}=0.67$ ) and almost $90 \%$ (mean 3.05, SD=2.03) of participants reported fever as useful, whereby they felt more confident the more they found fever useful. $69 \%$ of parents felt calm when their child has fever (mean 4.47, SD=2.27). In case of fever, $55 \%$ of parents administer paracetamol, $72 \%$ ibuprofen and $32 \%$ of them would alternate between the two. Paracetamol and ibuprofen are used more by more anxious parents. In explorative factor analysis, reasons to reduce temperature were summarised in three main factors: damage prevention, illness control and well-being protection, whereby the first two were positively related to parental anxiety.

Conclusions Both knowledge as well as level of confidence/anxiety vary largely. Taking antipyretics is related to higher level of anxiety, indicating the need for further education. Fever anxiety depends on multiple factors, which have to be further investigated.

\section{INTRODUCTION}

Paediatric fever is known as a source of anxiety in parents, leading to frequently unnecessary measures, such as physically or pharmaceutically lowering the body

\section{STRENGTH AND LIMITATIONS OF THIS STUDY}

$\Rightarrow$ Parents were recruited from healthy children, attending kindergarten; hence, parents were not under pressure of an unwell child.

$\Rightarrow$ Standardised values for fever anxiety were calculated from ordinal values.

$\Rightarrow$ Reasons to reduce fever were explored in a factor analysis.

$\Rightarrow$ More variables such as considering participants' different cultural backgrounds or timing/dosing of medications that parents administer could be included.

temperature and excessive visits to paediatric practices and emergency services. ${ }^{1-5}$ In 1980 , Schmitt ${ }^{2}$ introduced fever phobia, as parents' 'overconcern', that has been also defined as 'unrealistic and exaggerated misconceptions of parents' regarding fever. ${ }^{6}$ Given that clinical symptoms are missing as a criterion for phobia, in dimensional rather than categorical terms, the authors have opted to call this 'overconcern' anxiety, as a contrast to confidence. Considering the fact that fever is very common in young children and the fact that fever anxiety ('phobia') is still widely prevalent, ${ }^{78}$ many researchers have tried to understand the underlying parental perception about fever and its perceived harmful consequences. ${ }^{69}$

Despite scientific acknowledgement of fever as a useful body reaction in the course of the 20th century, ${ }^{10}$ there is evidence that a meaningful number of parents lack basic yet important information to overcome fear, to recognise warning signs and to manage their child's fever. ${ }^{3}$ This includes knowledge about normal and febrile temperature, ${ }^{3911}$ site of measurement and about fever being useful or harmful. ${ }^{3}$ This lack may lead to high levels of anxiety and mismanagement of fever, ${ }^{4}$ for example, by seeking refuge to 
over-the-counter medications, that is, antipyretics, to reduce the discomfort and temperature of the child. ${ }^{6}{ }^{12}$ Clinch and Dale suggested that the parents' anxiety is the most important element in their reactions and mismanagements regarding fever. ${ }^{4}$

Knowledge about fever, ${ }^{13}$ appropriate use of antipyretics, ${ }^{14}$ the level of anxiety ${ }^{9}$ and, in general, parental fever management ${ }^{131516}$ are reported to be different in various cultures. However, fever anxiety is found in all cultural backgrounds, including in Europe. ${ }^{9}$ This study reports findings from Germany, where to the best of our knowledge, there has been only one quantitative study on German parents on the subject of fever management in children. Langer et al did a cross-sectional study, where 338 parents with German and Turkish backgrounds were asked about their perceptions and actions regarding paediatric fever. The focus of their study was mainly on the influence of ethnicity background and socioeconomic status of participants, where they concluded that parents who experience fear tend to mismanage fever and need education about fever accordingly. Additionally, the annual reports on number of visits to practices, including paediatricians or family doctors, have indicated a high frequency of visits among Germans. ${ }^{17}$ Therefore, we find it necessary to investigate: (a) the parental level of confidence/anxiety, (b) motivation to reduce fever, (c) the existing knowledge and behaviour in fever management and (d) the corresponding elements with level of anxiety among German parents.

\section{METHODS}

\section{Study design, assessment and participant involvement}

After reviewing many articles regarding fever anxiety, a suitable questionnaire was designed based on the study's objectives. The questionnaire was based on the questions from Sakai $e t a l^{18}$ and Langer $e t a l^{1}$ studies. Once the first draft of the questionnaire was ready, 24 doctors and paediatricians reviewed it for face validity. Their comments were integrated and afterwards 10 random parents were requested to answer the questionnaire to see if it is understandable. After improvements, the final version was used, in which four questions were demographic questions, seven multiple choice, seven dichotomous, two Likert scale and five scale/numeric questions regarding temperature. Eight of these questions had a free text as well, in case, parents chose to add further details. Questions regarding medication, that is, fever reduction with paracetamol (acetaminophen), ibuprofen or alternating the two, were asked in five levels of 'often' (score 4), 'sometimes' (score 3), 'rarely' (score 2), 'never' (score 1) and 'I do not know' (considered as missing).

For categorical comparisons, the data were dichotomised arbitrary between a no answer (scores 1-2) and yes answer (scores 3-4) regarding administration of antipyretics. In the regression analysis, the corresponding scores were used. The question as to reasons for reducing temperature was a multiple-choice question with a possibility to choose multiple answers from 11 choices.

\section{Study setting}

A cross-sectional study in November 2017 and May 2018 was performed on German parents who were visiting one of the 16 participating kindergartens during the pickup time. The contact details of all kindergartens in Saarbrücken and Saarlouis regional association were found on the internet. ${ }^{19}$ Small kindergartens $(<50$ children) were excluded from study due to time constrains. At the time of study, 109 kindergartens were contacted via phone or email, out of which 16 of them accepted to cooperate with the researchers. The reasons for not participating included high proportion of non-Germanspeaking parents, participations in other studies or not having consent from the kindergarten's sponsor. Considering all kindergartens in the two districts (ie, Saarbrücken and Saarlouis) provided an expanded selection area and prevented selection bias. The parents were asked whether they would like to take part in a survey about fever management, then they received information about participation in the study along with a consent form. On their willingness to participate, they signed the consent form and answered the 25-item questionnaire. It took parents about 5-10 min per questionnaire, including reading the information and giving consent.

Inclusion criteria were good understanding of German and being a parent of at least one child below the age of 7 years. For the duration of the study, all children were healthy and without fever.

\section{Patient and public involvement}

The study's participants were parents, who first were involved to see if the questionnaire is understandable and comprehensive. The directors of kindergartens requested parents to participate in the study. The parents were not directly involved in the design and recruitment of this study. As the data collected were pseudonymised, the results could not be individually disseminated to participants. However, the results of this publication have been already conveyed to an existing parental group regarding fever. Additionally, these results will be disseminated in other related publications, and the lack of knowledge and level of fever anxiety will be considered in the German fever guideline, which is currently under development.

\section{Definitions}

German education system levels were translated into international classifications. To examine possible elements of 'fever phobia', introduced in this paper as 'fever anxiety', 13 questions (out of 25) were divided in three groups of 'knowledge', 'experience' and 'behaviour'. The remaining questions were not considered for these analyses, as they did not pass in the abovementioned categories. Where 'knowledge' consists of six questions about the basic knowledge of participants about fever: fever temperature, site of measurement, reasons for reducing 
A

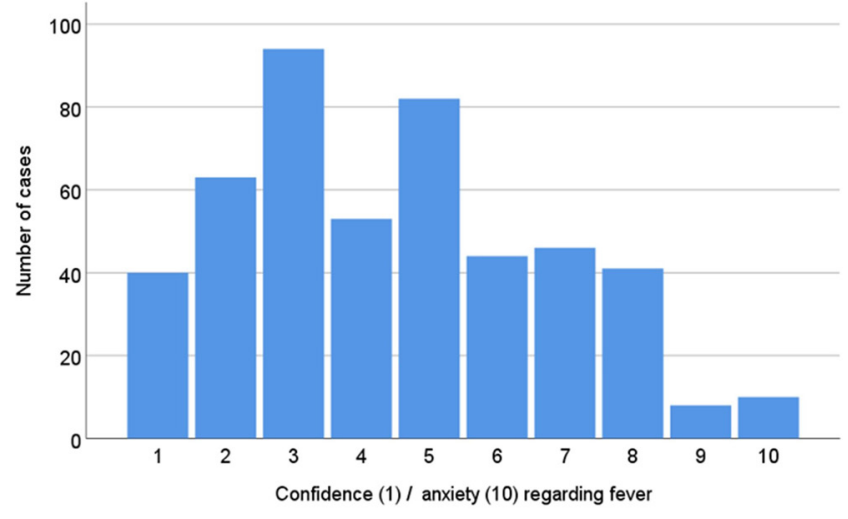

B

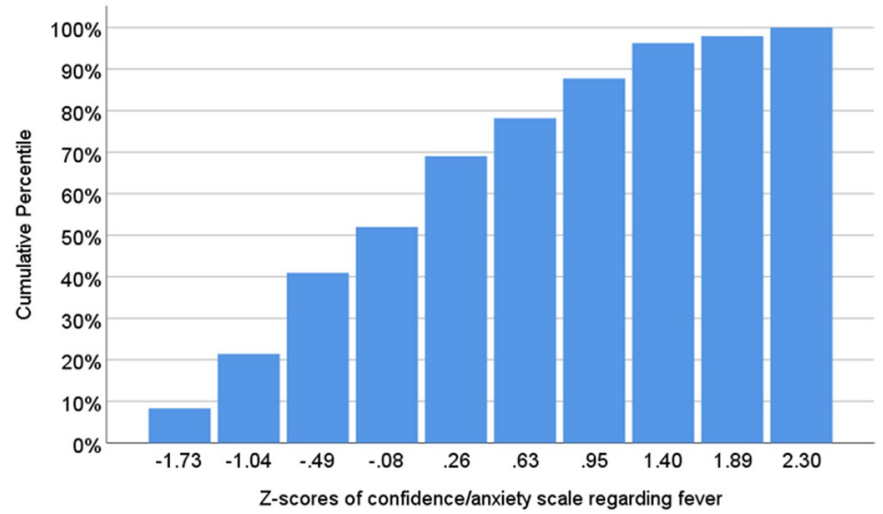

Figure 1 (A) 10-point Likert scale of confidence/anxiety scores. (B) Z-scores of confidence (negative values) /anxiety (positive values) scale regarding fever.

fever, the temperature above which medication is given, source of information and whether fever is considered useful or harmful. 'Experience' is defined by the knowledge gained related to the number of children in the family (the more children one has, the more experience they are expected to gain) and the experience gained by years of parenting (similar to Kelly et al, ${ }^{20}$ the age of the oldest child was used accordingly). 'Behaviour' includes four questions about administering antipyretics (ie, paracetamol and ibuprofen), use of naturopathic or homoeopathic medicine and non-medical behaviours such as calf wrap.

\section{Statistical analysis}

In contrast to previous studies, ${ }^{91621}$ we understand parental fever anxiety not primarily as categorical (worried/somewhat worried/not worried) but rather dimensional from confidence to anxiety. In this regard, parents estimated their level of confidence or anxiety on a 10-point Likert scale that indicates a broad distribution of how they feel when their child is feverish; 1 being feeling completely calm and safe and 10 being feeling restless and having anxiety (figure 1A). We performed a Z-transformation for the 10-point Likert scale of anxiety scores to normalise the distribution (figure 1A) and to share this for future studies. These scores were used in the regression analyses.
For categorical comparisons, the data were dichotomised arbitrarily between confident (scores 1-5) and anxious (scores 6-10).

Similar to confidence/anxiety, the knowledge of fever being useful or harmful was also evaluated on a similar 10-point Likert scale: 1 -fever being useful and 10being harmful. In the regression analysis, the Likert scale was used. For categorical comparisons, we dichotomised this scale between 1-5 (fever useful) and 6-10 (fever harmful).

Descriptive analysis was done on demographics and for the majority of questions for better understanding of data distribution. We performed an explorative factor analysis with Varimax rotation for 11 reasons of reducing temperature; frequency of answers is reported as binary. Further correlation and univariate linear regression were performed for studying the relationship among 'level of anxiety', 'knowledge', 'behaviour' and 'experience' components. A multiple linear regression was performed between the level of anxiety and significant components

Table 1 Participants' demographic information

\begin{tabular}{ll}
\hline Demographics & $\mathbf{N}(\%)$ \\
\hline Gender & \\
\hline Female & $394(81.9)$ \\
\hline Male & $86(17.9)$ \\
\hline No answer/missing & $1(0.2)$ \\
\hline Age (years) & \\
\hline $20-29$ & $41(8.5)$ \\
\hline $30-39$ & $273(56.8)$ \\
\hline $40-49$ & $147(30.6)$ \\
\hline$\geq 50$ & $4(0.8)$ \\
\hline No answer/missing & $16(3.3)$ \\
\hline
\end{tabular}

Education level (adopted from German system)

\begin{tabular}{ll} 
No school certificate & $5(1)$ \\
\hline High school & $43(8.9)$ \\
\hline College & $265(55.1)$ \\
\hline University degree & $153(31.8)$ \\
\hline No answer/missing & $15(3.1)$ \\
\hline Occupation & \\
\hline Without a job & $83(17.3)$ \\
\hline Part-time & $234(48.6)$ \\
\hline Full-time & $130(27)$ \\
\hline Retired & $10(2.1)$ \\
\hline Student & $3(0.6)$ \\
\hline No answer/missing & $21(4.4)$ \\
\hline Number of children & \\
\hline 1 & $163(33.9)$ \\
\hline 2 & $252(52.4)$ \\
\hline 3 & $66(13.7)$ \\
\hline
\end{tabular}


from the univariate analysis for a more in-depth understanding. The level of explorative significance is chosen $\mathrm{p}<0.05$. In case of missing data, the available data were analysed.

IBM SPSS, V.25 and 26 (IBM, Armonk, New York), was used for data analysis.

\section{RESULTS}

\section{Participants' characteristics}

In the current study, 481 parents answered a 25-item questionnaire on paper in 16 different kindergartens in the state of Saarland, Germany. Out of 481 participants, $82 \%$ were women. The mean and median age of mothers $(\mathrm{SD}=5$; range: $23-52)$ and fathers $(\mathrm{SD}=6$; range: $28-64)$ in years was $37(\mathrm{IQR}=33-41)$. One person did not provide information regarding their age and gender. Table 1 demonstrates the demographic information of participants. At the time of the study, most of the participants had two children (52.4\%), followed by one child (33.9\%), three children $(9.4 \%)$ and four children (4.3\%). Children's age range was $0-43$ years.

\section{Fever confidence/anxiety}

Within the dimensional spectrum between full confidence $(=1)$ and anxiety $(=10)$ the median level was 4 $(\mathrm{IQR}=3-6)$, and the mean was $4.47(\mathrm{SD}=2.27)$. Figure 1 shows the distribution of answers on the 10-point Likert scale and figure $1 \mathrm{~B}$ shows the corresponding standardised z-scores and percentiles. Negative z-scores or low percentiles correspond to confidence about fever and positive z-scores or high percentiles to increased fever anxiety. In binary analysis, $69 \%$ of participants reported that they feel calm when their child is feverish.

\section{Reasons for reducing fever}

To understand the relationship between the 11 response options to the question about reasons for reducing fever and its further analysis with fever anxiety, we performed a principal component analysis with Varimax rotation. Three independent factors were identified using the criteria Eigenvalue of at least 1 and scree plot of 11 response options, which together accounted for $47 \%$ of the variance. Table 2 presents the frequency of answers and the three semantic reasonable factors.

The first factor includes the three response options: 'prevent febrile seizures', 'prevent consequential damage from excessive temperatures' and 'prevent brain damage from febrile seizures'. We named this first factor 'damage prevention' (19\% variance resolution). The second factor includes four response options: 'improve physical wellbeing', 'improve psychological well-being', 'improvement in fluid intake' and 'reduction of strain of child', named as 'well-being protection' (15\% variance explanation). Interestingly 'improvement in fluid intake' loads as well on 'damage prevention'. As 'reduction of strain of child' had stronger correlation with response items in factor 2, whereas 'better participation in daily life' had a stronger correlation with response items in factor 3, they were grouped accordingly. Finally, the third factor includes four response options: 'faster recovery from underlying illness', 'better participation in daily life', 'parents' need for safety' and 'other reasons'. This factor was named as 'illness control' (13\% variance resolution). It is noteworthy that the answers written as a free text in 'other reasons' were mainly related to the topic of better sleeping.

\section{Understanding elements of fever confidence/anxiety}

To investigate the relationship between the aforementioned elements and fever anxiety, first a univariate linear regression analysis between level of anxiety and knowledge elements, behaviour elements, experience elements and demographics was performed. Standardised level of anxiety (z-value) was the dependent variable. Then, we performed a multivariate linear regression on significant elements in univariate

Table 2 Reasons to reduce temperature

\begin{tabular}{|c|c|c|c|c|}
\hline \multirow[b]{2}{*}{ Reasons for reducing fever } & \multirow[b]{2}{*}{$\mathbf{N}(\%)$} & \multicolumn{3}{|l|}{ Factors } \\
\hline & & $\begin{array}{l}\text { Factor } 1 \\
\text { Damage prevention }\end{array}$ & $\begin{array}{l}\text { Factor } 2 \\
\text { Well-being protection }\end{array}$ & $\begin{array}{l}\text { Factor } 3 \\
\text { IIIness control }\end{array}$ \\
\hline Prevent long-term damage from high temperature & $209(43.5)$ & 0.78 & -0.03 & 0.09 \\
\hline Prevent brain damage due to febrile seizures & $177(36.8)$ & 0.85 & 0.05 & 0.07 \\
\hline Improvement in fluid intake & $143(29.7)$ & 0.30 & 0.38 & 0.16 \\
\hline Reduction of strain of the child & $289(60.1)$ & $<0.01$ & 0.39 & 0.26 \\
\hline Better participation in daily life & $63(13.1)$ & 0.04 & 0.34 & 0.56 \\
\hline Parents' need to feel secure & $93(19.3)$ & 0.12 & 0.28 & 0.48 \\
\hline
\end{tabular}


Table 3 Linear regression analysis on level of anxiety regarding knowledge, behaviour and experience elements

\begin{tabular}{|c|c|c|c|c|c|c|c|}
\hline \multirow[b]{3}{*}{ Variables } & \multicolumn{7}{|l|}{ Level of anxiety } \\
\hline & \multicolumn{4}{|c|}{ Univariate linear regression analysis } & \multicolumn{3}{|c|}{ Multivariate linear regression analysis } \\
\hline & $\mathbf{N}(\%) /$ mean (SD) & $\mathbf{R}^{2}$ & B & P value & B & $95 \% \mathrm{Cl}$ & P value \\
\hline Education level (\%) & & & & & - & - & - \\
\hline No school certificate & $5(1)$ & 0 & -0.088 & 0.837 & - & - & - \\
\hline College & $265(55)$ & 0.003 & 0.103 & 0.247 & - & - & - \\
\hline University degree & $153(31.8)$ & 0.001 & -0.069 & 0.463 & - & - & - \\
\hline No answer/missing & $14(2.9)$ & - & - & - & - & - & - \\
\hline Age (years) (mean) & $37(5.37)$ & 0.014 & -0.021 & 0.011 & -0.005 & $(-0.027$ to 0.017$)$ & 0.65 \\
\hline Gender (male vs female) (\%) & $394(82)$ & 0.001 & -0.077 & 0.497 & - & - & - \\
\hline Parenting experience (years) & $6.05(4.29)$ & 0.006 & -0.017 & 0.089 & - & - & - \\
\hline \multicolumn{8}{|l|}{ Knowledge (mean) } \\
\hline Definition of fever in ${ }^{\circ} \mathrm{C}$ & $38.46(.67)$ & 0.018 & -0.19 & 0.003 & -0.14 & $(-0.303$ to 0.024$)$ & 0.094 \\
\hline \multicolumn{8}{|l|}{ Site of measurement (\%) } \\
\hline Rectal & $331(68.8)$ & 0.001 & -0.6 & 0.528 & - & - & - \\
\hline Oral & $21(4.4)$ & 0 & -0.024 & 0.912 & - & - & - \\
\hline Underarm & $45(9.4)$ & 0.005 & 0.229 & 0.126 & - & - & - \\
\hline Ear & $226(47)$ & \multirow{2}{*}{$\begin{array}{l}0 \\
0.003\end{array}$} & \multirow{2}{*}{$\begin{array}{l}0.038 \\
-0.336\end{array}$} & \multirow{2}{*}{$\begin{array}{l}0.662 \\
0.211\end{array}$} & \multirow[t]{2}{*}{-} & \multirow[t]{2}{*}{-} & \multirow[t]{2}{*}{-} \\
\hline Forehead & $13(2.7)$ & & & & & & \\
\hline \multicolumn{8}{|l|}{$\begin{array}{l}\text { Reason for reducing fever } \\
\text { (mean) }\end{array}$} \\
\hline $\begin{array}{l}\text { Temperature threshold for } \\
\text { medication in }{ }^{\circ} \mathrm{C} \text { (mean) }\end{array}$ & $39.05(0.65)$ & 0.047 & -0.317 & $<0.001$ & -0.47 & $(-0.257$ to 0.164$)$ & 0.663 \\
\hline \multicolumn{8}{|l|}{ Source of information (\%) } \\
\hline Paediatrician (doctor) & $348(72.3)$ & 0.005 & 0.147 & 0.131 & - & - & - \\
\hline Family & $362(75.3)$ & 0.002 & 0.09 & 0.374 & - & - & - \\
\hline Internet & $112(23.3)$ & 0.012 & 0.246 & 0.017 & 0.232 & $(-0.036$ to 0.501$)$ & 0.089 \\
\hline $\begin{array}{l}\text { Fever is useful or harmful } \\
\text { (mean) }\end{array}$ & $3.05(2.03)$ & 0.146 & 0.179 & $<0.001$ & 0.119 & (0.056 to 0.182$)$ & $<0.001$ \\
\hline \multicolumn{8}{|l|}{ Behaviour (mean) } \\
\hline Paracetamol & $2.53(.93)$ & 0.033 & 0.186 & $<0.001$ & 0.247 & (0.118 to 0.375$)$ & $<0.001$ \\
\hline Ibuprofen & $2.91(.89)$ & 0.009 & 0.980 & 0.044 & 0.161 & (0.030 to 0.292$)$ & 0.016 \\
\hline Alternating & $1.93(1.02)$ & 0.004 & 0.059 & 0.176 & - & - & - \\
\hline Measures- Calf wrap (\%) & $225(46.8)$ & 0.018 & -0.454 & 0.033 & -0.503 & $(-0.906$ to -0.101$)$ & 0.014 \\
\hline
\end{tabular}

Positive ß-values indicate increased anxiety, negative values indicate more confidence. 
analysis to investigate different models on factors influencing fever management. The results are displayed in table 3 .

\section{Fever management: knowledge and behaviour Knowledge}

To investigate the basic knowledge of parents about fever, we asked from which temperature they talk about fever. The range of responses was from $30^{\circ} \mathrm{C}$ to $40.1^{\circ} \mathrm{C}$ (mean $38.46^{\circ} \mathrm{C}, \mathrm{SD}=0.67$ ), in which $30.6 \%$ of parents reported $38^{\circ} \mathrm{C}$ as fever, $29.5 \%$ reported $38.5^{\circ} \mathrm{C}$ and $26 \%$ reported $39^{\circ} \mathrm{C}$. The most frequent sites of measurement used were rectum $(69 \%)$ and ear $(47 \%)$; multiple answers were possible (table 3). Additionally, a significant relationship between site of measurement and children's age was not found. On the subject of fever being useful or harmful, in binary analysis (mean $3.05, \mathrm{SD}=2.03$ ), $89.6 \%$ of parents found fever useful.

To understand the criteria on which parents base their considerations to administer antipyretics, they were asked if giving it is dependent (a) on the temperature and/or (b) any other criteria. Regarding (a), $84 \%$ of parents reported that it is dependent on temperature, where the range was from $36^{\circ} \mathrm{C}$ to $41^{\circ} \mathrm{C}$ (mean $39^{\circ} \mathrm{C}$, $\mathrm{SD}=0.65$ ). Only $3 \%$ of participants would administer antipyretics below $37.75^{\circ} \mathrm{C}$ and $70 \%$ of parents would do it from temperatures above $39^{\circ} \mathrm{C}$. Regarding (b), $117(24 \%)$ of parents reported the general condition of their child as the criteria. Additionally, most parents felt well informed and advised by their paediatrician about fever $(80 \%)$ and antipyretics $(81 \%)$. The most frequent answers to parents' source of information are summarised in table 3 .

\section{Behaviour}

Participants were asked whether they administer paracetamol, ibuprofen or alternate the two to reduce their child's fever. Parents responded that they would administer paracetamol often $(13.7 \%)$, sometimes $(41.6 \%)$, rarely $(26.4 \%)$, never $(16.8 \%)$; and seven responses $(1.5 \%)$ were missing. Parents reported they would administer ibuprofen often $(27.7 \%)$, sometimes $(43.9 \%)$, rarely $(18.7 \%)$, never $(8.5 \%)$; and six $(1.2 \%)$ were missing. Of $46.8 \%$ of parents reported never alternating paracetamol and ibuprofen, $19.8 \%$ rarely, $24.3 \%$ sometimes and $8.1 \%$ often; five responses $(1 \%)$ were missing. Through binary analysis, ibuprofen (72\%) seems to be preferred over paracetamol $(56 \%)$. Two-third $(66.5 \%)$ of parents would not alternate paracetamol and ibuprofen.

To the question of home remedies applied at home to reduce children's temperature, 227 answers were recorded, in which $95 \%(\mathrm{n}=216)$ of parents mentioned using calf wraps. Other frequent measures mentioned were forehead compress (5\%), using damp cloths (4\%), and increase of liquid intake $(3.5 \%)$. Only $17 \%$ of parents specifically reported using naturopathic or homeopathic medicines to reduce fever.

\section{DISCUSSION}

As parents are the important source of monitoring when a child is unwell, their accurate knowledge is crucial. In this regard, we investigated German parents' level of knowledge, reported behaviour and level of confidence/ anxiety regarding fever, using a self-administered questionnaire. Where most studies have recruited parents from healthcare centres with unwell children, ${ }^{3}{ }^{29}$ we recruited parents when they were not under the pressure of having an unwell child, as child's sickness could increase parents' anxiety. ${ }^{23}$ Also, considering that anxiety could be experienced even without the presence of the stimulus, ${ }^{24}$ we find this kind of approach in understanding parental knowledge and behaviour necessary, despite the argument that a self-report in a hypothetical situations may not be trustworthy. ${ }^{25}$

Based on the parental guideline of the German Society of Pediatrics and Adolescent Medicine (Deutsche Gesellschaft für Kinder-und Jugendmedizin, DGKJ), ${ }^{26}$ a febrile temperature is defined as $\geq 38.5^{\circ} \mathrm{C}$. Only $29.5 \%$ of parents in our study chose the correct temperature as fever. Additionally, $30.6 \%$ of parents considered $38^{\circ} \mathrm{C}$ as fever, which is still a low level of knowledge in comparison with other studies considering fever as $38^{\circ} \mathrm{C}^{22} 2728$ However, $69 \%$ of parents indicated rectal temperature measurement as the preferably used site of measurement, which is in unison with the DGKJ parental guideline. A comparison with other studies ${ }^{142122 \text { 28-30 }}$ shows that site of temperature measurement varies culturally, where rectal measurement is more often used in European countries. Fever is recognised as being advantageous in most cases of infection, ${ }^{31}{ }^{32}$ indicating a healthy body reaction in fighting underlying pathogens. ${ }^{12}$ In the present study, when parents were asked if fever is useful or harmful, almost $90 \%$ of the parents recognised it as useful. Even though, some qualitative studies found similar findings, ${ }^{15} 33$ the majority of quantitative studies report the contrary. ${ }^{310}$ Multivariate regression analysis showed that the more parents find fever harmful, the more anxiety they experience. Despite finding fever useful, parents had concerns regarding its perceived potential harmful effects. This could indicate the inconsistency of knowledge about fever among parents. Literature review suggests that the majority of parents have anxiety about fever due to the notion that if not treated, it can have harmful effects. Brain damage and febrile seizures are the most frequently mentioned harmful effects that parents fear in the literature, ${ }^{10}$ whereas, in the present study, parents were mostly worried about physical well-being $(75 \%)$ and reduction of child's strain $(60 \%)$, followed by febrile seizures $(56 \%)$, then brain damage $(36.8 \%)$ and dehydration $(29.7 \%)$. Although, as dehydration was more rarely a reason to reduce fever in previous studies, ${ }^{2} 34$ the similar findings by Kelly $e t a l^{20}$ suggest that an enhancement of knowledge can be achieved among parents. However, as Kelly et al's study was also conducted in Europe, the effect of cultural differences here has to be further studied. 
In the current study, the answer to level of anxiety was distributed in a wide range, demonstrating the distribution of parental feelings. Univariate regression analysis (table 3) showed that the higher the parent's age, the more they feel confident in managing their child's fever. These findings are in contrary to the study done by Langer et $a l,{ }^{1}$ where they did not find any relationship between the two. Using the same analysis, we found increased confidence with increase in number of children. This finding is similar to that of Betz et al, ${ }^{9}$ where parents with one child in comparison with parents with two or more children were more likely to be anxious, when their child has fever. However, we did not find any significant relationship between years of parenting, parents' education level, gender and level of anxiety. It is noteworthy that ways parents notice fever (eg, with touching forehead or using thermometer), measuring temperature repeatedly and reasons for contacting paediatricians may be indicators of parental anxiety that could be additionally investigated. As fever anxiety influences the management of fever, it is helpful to know the reasons that provoke parents to reduce their child's temperature. Through an explorative factor analysis, 11 reasons for fever reduction were, as far as we know for the first time, categorised in three main aspects, that is, damage prevention, wellbeing protection and illness control. Based on regression analysis (table 3), prevention of damage and control of illness are positively connected to higher level of parental anxiety. Parents seem to take measurements, in order to, first, have their child back to their normal state and, second, protect them from any harm. These findings confirm Langer et als speculations that 'maternal actions can be understood' as protecting their child from harm. ${ }^{13}$

Consistent with other studies, parents reported using antipyretics to reduce temperature. One explanation could be that parents feel more anxious when they find fever harmful and, therefore, administer antipyretics (table 3). Hence, especially in anxious parents, it is important to know whether they have sufficient knowledge about administering antipyretics as unappropriated dosing or timings could lead to unintentional poisoning. ${ }^{35}$ Therefore, future studies should consider investigating the timing/dosing of medication administration by parents, in order to have a better understanding of this aspect in parental fever management. One reason behind the frequent use of antipyretics is the fear of fever and its consequences, ${ }^{23}$ whereas mostly paracetamol has been favoured among parents, ${ }^{72}{ }^{36}$ German parents seem to administer ibuprofen more than paracetamol (72\% vs $56 \%$ ). A study on German adults regarding use of analgesic medication reported similar results, where ibuprofen was used more often than paracetamol. ${ }^{37}$ One explanation for using ibuprofen could be its dosing and its longer effect advantages. ${ }^{38} \mathrm{An}$ increased awareness for side effects of paracetamol (liver failure, ${ }^{39}$ asthma, ${ }^{40} 41$ etc) may also explain the trend towards ibuprofen in the past decade. In the current study, parents reported to use antipyretics at comparatively higher temperatures (mean $=39.05, \mathrm{SD}=0.65)$ than in earlier studies, where antipyretics are administered at or below normal temperature (below $38^{\circ} \mathrm{C}$ ). ${ }^{2} 2034$ An inverse relationship between level of anxiety and the temperature above which medication is given was found, where the higher temperature indicated more confidence. The same was applied to level of anxiety and parents' definition of fever (ie, the temperature they recognise as fever). The multivariate regression showed that the administration of paracetamol and ibuprofen could be indicators of higher level of anxiety. Guidelines have been encouraging parents to focus on their child's overall well-being before administering antipyretics and not only focus on decreasing body temperature. $^{42}$ On this subject, $52 \%(\mathrm{n}=224)$ of the parents reported they first observe the overall condition of their child before administering antipyretics, and $70 \% \quad(\mathrm{n}=481)$ of parents would consider reducing temperature above the temperature of $39^{\circ} \mathrm{C}$. These are encouraging results in comparison to previous studies. Additionally, the DGKJ recommends abdominal or calf wrap as a non-medical method to reduce high fever. ${ }^{26}$ Almost $45 \%$ of parents in a free text question wrote that they use calf wraps to reduce their child's body temperature.

Many authors have suggested that the doctors, who are often the first and most trusted source of information, should make sure to establish that parents' knowledge of fever management is adequate. Especially for worried parents, straightforward and clear communication is necessary. ${ }^{2}{ }^{23}$ Although, in the majority of studies, the common source of information was healthcare professionals, ${ }^{44}$ this study's participants reported first their family and then their doctor as the source of information about paediatric fever. Depending on the cultural context, information given by family members may increase the level of parental anxiety. ${ }^{43}$ In agreement with other studies, ${ }^{45}$ internet as a source of information seems to be related to an increased level of anxiety. As suggested by Kravitz and Bell, ${ }^{46}$ the current problem we face is the recognition of trustworthy sources. Considering that $53 \%$ of Germans search their symptoms in internet ${ }^{47}$ (vs 23\% in current study), it is important for healthcare personnel to have a clear and informative communication with their patients. Eighty per cent of parents surveyed in the current study reported trusting the information they receive from their paediatricians, which is higher than the average of $62 \%$ of Germans who report trusting healthcare. ${ }^{48}$ Nevertheless, given the time constraints of paediatricians, other means of transferring and securing information should be considered.

In summary, in adjusted multivariate analysis, we found a relationship between lower level of confidence (ie, higher level of anxiety) and (1) understanding fever as harmful, (2) illness control as a reason for reducing fever, (3) using calf wraps to reduce temperature, (4) administrating paracetamol and (5) administering ibuprofen. The fact that most of the significant elements correlated with parental anxiety in multivariate linear regression are related to the measures parents take (ie, behaviour elements), which suggests the need for educating parents about fever and safe ways to handle it. Through the analysis, we could enhance the questions in the questionnaire, in order it could be used for future studies. This includes adding more items such as giving 
medication, so that the child sleeps better or the frequency of temperature measurements. Additionally, through the factor analysis of 'reasons to reduce temperature', we could show a good construct validity and inter-reliability of these items. To the best of our knowledge, no other study tried to analyse possible features of fever anxiety, generally known as 'fever phobia'. Needless to say, cross-sectional studies have some limitations. Specifically, the collected data are observational and causal conclusions could not be drawn. Additionally, larger sample size would enhance further analyses. Therefore, there is a strong need for representative, longitudinal and ecological momentary assessment studies ${ }^{49}$ that could help to achieve more understanding of parental behaviour and anxiety in treating paediatric fever. Furthermore, the influence of cultural differences needs to be precisely considered, especially in countries such as Germany, where the immigration rates are noteworthy.

\section{CONCLUSION}

Even though the majority of parents surveyed in this study reported feeling calm and confident in managing fever, there are still inconsistences in their knowledge about fever and their fever management. It is surprising that even though many parents know fever is useful, some do not know what temperature is considered as fever. Parents experience various levels of anxiety about perceived potential harms of fever, for which this study, for the first time, explored the reasons in detail. The intention to have one's child in their normal, non-symptomatic status and the intention to prevent any harm was correlated with parental anxiety. As parents are the important source of monitoring, they need to be educated and informed about fever, its benefits, warning signs and its management. Cultural background influences need to be taken into account in future studies and for interventions to increase parental knowledge.

Acknowledgements We are thankful to all participating kindergartens and parents. This study is part of C.H. medical thesis.

Contributors The study and the questionnaire were designed by DDM and $\mathrm{CH}$. Data collection, communication with kindergartens and participants were done by $\mathrm{CH}$. Essential manuscript writing was done by SHK. Calculations and interpretations were done by SHK and EJ. All authors approved the final manuscript. Responsible for the conduct of the study was DDM and for the data and publication was EJ.

Funding The authors have not declared a specific grant for this research from any funding agency in the public, commercial or not-for-profit sectors.

Competing interests None declared.

Patient consent for publication Not applicable.

Ethics approval The parents were asked if they would like to take part in a survey about fever management, then they received information about participation in the study along with a consent form. The study, the questionnaire and the consent form were approved by the ethics committee of the Medical Association of Saarland (number 107/17, on 13 February 2018). All methods were carried out in accordance with national law and in accordance with the Declaration of Helsinki (1964, as currently revised in 2013).

Provenance and peer review Not commissioned; externally peer reviewed.

Data availability statement Data are available upon reasonable request. The datasets analyzed during the current study are available from the corresponding author on reasonable request.
Open access This is an open access article distributed in accordance with the Creative Commons Attribution Non Commercial (CC BY-NC 4.0) license, which permits others to distribute, remix, adapt, build upon this work non-commercially, and license their derivative works on different terms, provided the original work is properly cited, appropriate credit is given, any changes made indicated, and the use is non-commercial. See: http://creativecommons.org/licenses/by-nc/4.0/.

ORCID iDs

Sara Hamideh Kerdar http://orcid.org/0000-0001-7479-8607

Ekkehart Jenetzky http://orcid.org/0000-0001-5415-8784

\section{REFERENCES}

1 Langer T, Pfeifer M, Soenmez A, et al. Fearful or functional--a crosssectional survey of the concepts of childhood fever among German and Turkish mothers in Germany. BMC Pediatr 2011;11:41.

2 Schmitt BD. Fever phobia: misconceptions of parents about fevers. Am J Dis Child 1980;134:176-81.

3 Bong W-T, Tan C-E. Knowledge and concerns of parents regarding childhood fever at a public health clinic in Kuching, East Malaysia. Open Access Maced J Med Sci 2018;6:1928-33.

4 Clinch J, Dale S. Managing childhood fever and pain--the comfort loop. Child Adolesc Psychiatry Ment Health 2007;1:7.

5 de Bont EGPM, Lepot JMM, Hendrix DAS, et al. Workload and management of childhood fever at general practice out-of-hours care: an observational cohort study. BMJ Open 2015;5:e007365.

6 Gunduz S, Usak E, Koksal T, et al. Why fever phobia is still common? Iran Red Crescent Med J 2016;18:e23827.

7 Purssell E. Parental fever phobia and its evolutionary correlates. $J$ Clin Nurs 2009;18:210-8.

8 Chiappini E, Cangelosi AM, Becherucci P, et al. Knowledge, attitudes and misconceptions of Italian healthcare professionals regarding fever management in children. BMC Pediatr 2018;18:194.

9 Betz MG, Grunfeld AF. 'Fever phobia' in the emergency department: a survey of children's caregivers. Eur J Emerg Med 2006;13:129-33.

10 Adeboye A, Yusuf RA, Ige OK. Fever: a literature review of perceptions, perspectives and practices. J Tradit Med Clin Naturop 2017;06:249.

11 Poirier MP, Collins EP, McGuire E. Fever phobia: a survey of caregivers of children seen in a pediatric emergency department. Clin Pediatr 2010;49:530-4.

12 Corrard F, Copin C, Wollner A, et al. Sickness behavior in feverish children is independent of the severity of fever. An observational, multicenter study. PLoS One 2017;12:e0171670.

13 Langer T, Pfeifer M, Soenmez A, et al. Activation of the maternal caregiving system by childhood fever--a qualitative study of the experiences made by mothers with a German or a Turkish background in the care of their children. BMC Fam Pract 2013;14:35.

14 Crocetti M, Sabath B, Cranmer L, et al. Knowledge and management of fever among Latino parents. Clin Pediatr 2009;48:183-9.

15 Bertille N, Purssell E, Corrard F, et al. Fever phobia 35 years later: did we fail? Acta Paediatr 2016;105:9-10.

16 Chang L-C, Liu C-C, Huang M-C. Parental knowledge, concerns, and management of childhood fever in Taiwan. $J$ Nurs Res 2013;21:252-60.

17 Grobe TG, Steinmann S. Szecsenyi J. Arztreport 2019, Schriftenreihe Zur Gesundheitsanalyse. Barmer, 2019.

18 Sakai R, Niijima S, Marui E. Parental knowledge and perceptions of fever in children and fever management practices: differences between parents of children with and without a history of febrile seizures. Pediatr Emerg Care 2009;25:231-7.

19 Saarbrücken K-PR. Available: https://www.kitaplatz-regionalverband. de/elternportal/de/einrichtungen/liste [Accessed 16 Aug 2021].

20 Kelly M, Sahm LJ, Shiely F, et al. Parental knowledge, attitudes and beliefs on fever: a cross-sectional study in Ireland. BMJ Open 2017;7:e015684.

21 Rupe A, Ahlers-Schmidt CR, Wittler R. A comparison of perceptions of fever and fever phobia by ethnicity. Clin Pediatr 2010;49:172-6.

22 Hussain SM, Al-Wutayd O, Aldosary AH, et al. Knowledge, attitude, and practice in management of childhood fever among Saudi parents. Glob Pediatr Health 2020;7:2333794X2093161.

23 Kelly M, McCarthy S, O'Sullivan R, et al. Drivers for inappropriate fever management in children: a systematic review. Int J Clin Pharm 2016;38:761-70.

24 Hartley CA, Phelps EA. Anxiety and decision-making. Biol Psychiatry 2012;72:113-8.

25 Usherwood TP. How valid are responses to questions about behaviour in hypothetical illness situations? J Public Health Med 1991;13:115-9. 
26 Ed D. Mein Kind hat Fieber". Available: https://www.dgkj.de/eltern/ dgkj-elterninformationen/elterninfo-fieber2018 [Accessed 30 Dec 2020]

27 de Bont EG, Francis NA, Dinant G-J, et al. Parents' knowledge, attitudes, and practice in childhood fever: an Internet-based survey. Br J Gen Pract 2014;64:e10-16.

28 Cohee LMS, Crocetti MT, Serwint JR, et al. Ethnic differences in parental perceptions and management of childhood fever. Clin Pediatr 2010;49:221-7.

29 de Bont EGPM, Loonen N, Hendrix DAS, et al. Childhood fever: a qualitative study on parents' expectations and experiences during general practice out-of-hours care consultations. BMC Fam Pract 2015;16:131.

30 Barutcu A, Barutcu S. Evaluation of knowledge, attitudes and practices of parents presenting to a hospital emergency department with a complaint of fever in a child. Signa Vitae 2020;16:123-9.

31 González Plaza JJ, Hulak N, Zhumadilov Z, et al. Fever as an important resource for infectious diseases research. Intractable Rare Dis Res 2016;5:97-102.

32 Evans SS, Repasky EA, Fisher DT. Fever and the thermal regulation of immunity: the immune system feels the heat. Nat Rev Immunol 2015;15:335-49.

33 Sahm LJ, Kelly M, McCarthy S, et al. Knowledge, attitudes and beliefs of parents regarding fever in children: a Danish interview study. Acta Paediatr 2016;105:69-73.

34 Crocetti M, Moghbeli N, Serwint J. Fever phobia revisited: have parental misconceptions about fever changed in 20 years? Pediatrics 2001;107:1241-6.

35 Azab SMS, Hirshon JM, Hayes BD, et al. Epidemiology of acute poisoning in children presenting to the poisoning treatment center at Ain Shams university in Cairo, Egypt, 2009-2013. Clin Toxicol 2016;54:20-6.

36 Kamel F, Magadmi R, AbuOuf NM, et al. Knowledge, attitude, and practice of paracetamol and ibuprofen administration among caregivers of the pediatric age group in Jeddah. Cureus 2021;13:e12460.

37 Sarganas G, Buttery AK, Zhuang W, et al. Prevalence, trends, patterns and associations of analgesic use in Germany. BMC Pharmacol Toxicol 2015;16:28.
38 van den Anker JN. Optimising the management of fever and pain in children. Int J Clin Pract Suppl 2013;178:26-32.

39 Murray KF, Hadzic N, Wirth S, et al. Drug-Related hepatotoxicity and acute liver failure. J Pediatr Gastroenterol Nutr 2008;47:395-405.

40 Sakulchit T, Goldman RD. Acetaminophen use and asthma in children. Can Fam Physician 2017;63:211-3.

41 McCrae JC, Morrison EE, Maclntyre IM, et al. Long-term adverse effects of paracetamol - a review. Br J Clin Pharmacol 2018;84:2218-30.

42 NICE. Fever in under 5S: assessment and initial management, 2019. Available: https://www.nice.org.uk/guidance/ng143/chapter/ Recommendations [Accessed 29 Jan 2021].

43 Avner JR, Baker MD. Management of fever in infants and children. Emerg Med Clin North Am 2002;20:49-67.

44 Thompson AP, Nesari M, Hartling L, et al. Parents' experiences and information needs related to childhood fever: a systematic review. Patient Educ Couns 2020;103:750-63.

45 Barke A, Doering BK. Development of an Instrument to Assess Parents' Excessive Web-Based Searches for Information Pertaining to Their Children's Health: The "Children's Health Internet Research, Parental Inventory" (CHIRPI). J Med Internet Res 2020;22:e16148.

46 Kravitz RL, Bell RA. Media, messages, and medication: strategies to reconcile what patients hear, what they want, and what they need from medications. BMC Med Inform Decis Mak 2013;13 Suppl 3:S5.

47 Bitkom. Jeder Zweite recherchiert seine Krankheitssymptome Im Netz, 2020. Available: https://www.bitkom.org/Presse/ Presseinformation/Jeder-Zweite-recherchiert-seineKrankheitssymptome-im-Netz; [Accessed 24 Dec 2020].

48 Edelman. Trust in healthcare: global, 2019. Available: https:// www.edelman.com/sites/g/files/aatuss191/files/2019-04/2019 Edelman_Trust_Barometer_Global_Health_Report.pdf?utm_source= downloads\&utm_campaign=trust_barometer; [Accessed 24 Dec 2020].

49 Martin D, Wachtmeister J, Ludwigs K, et al. The FeverApp registry - ecological momentary assessment (EMA) of fever management in families regarding conformity to up-to-date recommendations. BMC Med Inform Decis Mak 2020;20:249. 